\title{
Prevalence and associated risk factors of asymptomatic bacteriuria among antenatal women attending a health care center: one year study
}

\author{
Vijayalakshmi Cooly, Sailaja Bandaru*, Bhuvaneswari Salicheemala, Sailaja Surayapalem
}

Department of Obstetrics and Gynecology, Narayana Medical College, Nellore, Andhra Pradesh, India

Received: 25 September 2017

Accepted: 30 October 2017

\section{*Correspondence:}

Dr. Sailaja Bandaru,

E-mail: sujatha2481@gmail.com

Copyright: (C) the author(s), publisher and licensee Medip Academy. This is an open-access article distributed under the terms of the Creative Commons Attribution Non-Commercial License, which permits unrestricted non-commercial use, distribution, and reproduction in any medium, provided the original work is properly cited.

\begin{abstract}
Background: Asymptomatic bacteriuria is defined as presence of persistent and actively multiplying bacteria in urine in significant numbers, $\geq 105 / \mathrm{ml}$ but without clinical symptoms. Detection of ASB is important during pregnancy as it leads to $25 \%$ of symptomatic urinary tract infection in pregnant mothers, pyelonephritis, hypertension in pregnancy, postpartum UTI, anemia, preterm labour, low birth weight and perinatal death of the foetus. The objective of the present study is to identify the prevalence of ASB among pregnant women, epidemiological pattern, risk factors associated with it, type of pathogens and their antimicrobial susceptibility.

Methods: A prospective cross-sectional study was conducted on 500 asymptomatic antenatal women who fulfilled the inclusion criteria attending the department of Obstetrics and Gynecology. Mid stream urine specimen was collected from all the cases and subjected to microscopic analysis and culture and sensitivity.

Results: Our study showed the prevalence of ASB as 7.6\% among antenatal women.78.8\% of sterile cases and $13.6 \%$ as contaminants. 21-25 years was the common age group of ASB cases in our study. ASB was common among multiparous women, during $3^{\text {rd }}$ trimester. Statistically significant association was observed with low socio-economic status, increases sexual activity and among illiterate cases. Escherichia coli $(42.11 \%)$ was the most common isolate in the study. Other isolates were Klebsiella, Staphylococcus aureus, CONS, Citrobacter and Enterococcus sp. Imipenem, Meropenem exhibited $100 \%$ sensitivity for gram negative isolates and clindamycin for gram positive isolates.

Conclusions: All the cases of ASB diagnosed should be treated based upon the culture and sensitivity report to prevent unnecessary prescription of antibiotics which can economically burden the patient as well pave a way in development of resistant strains. Hence, further initiatives should be undertaken to include urine culture sensitivity as a part of national screening programme to prevent maternal and foetal complications.
\end{abstract}

Keywords: Antenatal women, Asymptomatic bacteriuria, Escherichia coli, Low birth weight, Preterm labour, Urinary tract infection

\section{INTRODUCTION}

Urinary tract infections (UTI) are one of the most common infections during pregnancy and are symptomatic and asymptomatic. UTI as such are more common in females due to short urethra, close proximity of perineal area and tend to occur more commonly during pregnancy because of physiological and hormonal changes. ${ }^{1}$ Increase in the size of uterus with gestational age leads to urinary stasis and retention which causes both symptomatic and asymptomatic bacteriuria [ASB] during pregnancy. Asymptomatic bacteriuria is defined as presence of persistent and actively multiplying bacteria in urine in significant numbers, $\geq 10^{5} / \mathrm{ml}$ but without clinical symptoms.

Most of the studies conducted globally have reported the incidence of ASB as 2-10\% depending upon the place 
and region. Few of the studies in India have reported the incidence as $8-10 \%$. Detection of ASB is important during pregnancy as it leads to $25 \%$ of symptomatic UTI in pregnant mothers, pyelonephritis, hypertension in pregnancy, postpartum UTI, anemia, preterm labour, low birth weight and perinatal death of the foetus. ${ }^{2}$ Most of the studies have shown that early detection and management of ASB during pregnancy may reduce maternal morbidity and reduces the foetal complications associated with it. ${ }^{3}$

Hence most of the studies have advocated urine examination with culture as an effective screening tool in detection of cases of ASB in pregnant mothers to prevent development of complications. ${ }^{4}$ A single urine specimen obtained from 12-16 weeks of pregnancy will identify most women with ASB. Escherichia coli being the most commonly isolated pathogen accounting for $70 \%$ of infections. These pathogens exist as natural periurethral commensal and ascend the route leading to ASB and UTI. However, the frequencies of isolated pathogens and their antimicrobial susceptibility differ from place to place and region to region. ${ }^{5}$ The objective of the present study is to identify the prevalence of ASB among pregnant women, epidemiological pattern, risk factors associated with it, type of pathogens and their antimicrobial susceptibility.

\section{METHODS}

A prospective cross sectional study was conducted by Department of Obstetrics and Gynecology in association with Department of Microbiology at Narayana Medical College and hospital, a tertiary care hospital, for a period of 12 months from April 2016 to March 2017. A total of 500 pregnant women attending the antenatal clinic were recruited in the study after obtaining their consent.

Demographic data, socioeconomic history, obstetric history including gravida, parity and period of gestation were collected by interviewing the cases and data was entered in a pre prepared proforma. Special attention was focused on history of antibiotic usage before 2 weeks, previous and present history of urinary tract infection, known diabetes mellitus; congenital anomalies of urinary tract, recent history of Catheterization, immunosuppressive therapy was excluded from the study. The study was approved by the institutional ethical committee.

\section{Specimen collection}

All the participants in the study were counseled about the study and informed about the "Clean catch mid-stream technique" of urine collection and precautions to be followed. $5-10 \mathrm{ml}$ of urine is collected in a wide mouthed sterile screw capped container and sent to laboratory immediately or within 2 hours. Specimen was observed macroscopically and divided into two portions, one for microscopy and other for culture and sensitivity.

\section{Microscopic examination}

One drop of centrifuged deposit of urine obtained after centrifugation of specimen at 3000rpm for 15-20 minutes was put on a new clean glass slide and observed for pus cells, casts, bacteria and RBC.

\section{Culture and sensitivity}

Aerobic bacterial culture was performed by using "Standard loop technique" and followed semi quantitative culture method. A calibrated loop carrying $0.01 \mathrm{ml}$ of urine was used and well mixed urine specimen was streaked on well dried sterile plates of Macconkey agar, blood agar and Cysteine electrolyte deficient agar and incubated at $37^{\circ} \mathrm{C}$ for overnight. Plates were examined next day, and colony counts were estimated and expressed as Colony forming units/ml (CFU/ml). Specimens providing $\geq 10^{5} \mathrm{CFU} / \mathrm{ml}$ were considered significant and further processed. All the isolates in the culture were further processed and identified by standard microbiological methods. Antibiotic sensitivity of the isolates was further done by standardized Kirby- Bauer disc diffusion method and interpretations were carried out accordingly by following NCCLS guidelines. ${ }^{6}$

\section{Statistical analysis}

Data was entered into Microsoft excel spread sheet and analyzed using Graphpad Prism version 4.0. A p value $<0.005$ was considered statistically significant.

\section{RESULTS}

In the present prospective study, out of 500 asymptomatic pregnant women attending the antenatal clinic, asymptomatic bacteriuria was found in 38 cases $(7.6 \%)$ and was significant while 394 cases $(78.8 \%)$ showed no growth and in 68 cases $(13.6 \%)$ contaminants were grown (Figure 1).

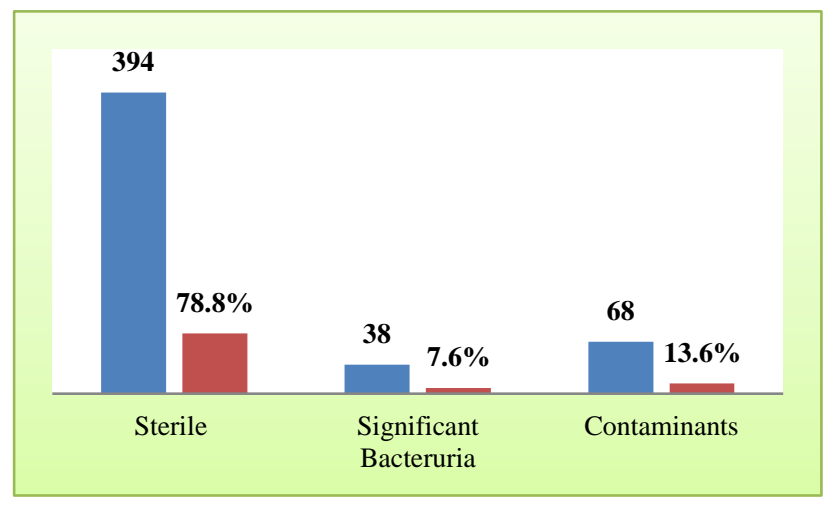

Figure 1: Results of culture.

Prevalence of ASB in the present study was 7.6\%. The highest number of culture positive cases were seen in the age group of $21-25$ years $(47.37 \%)$ followed by $26-30$ years $(26.32 \%)$. The mean age of the participants in the 
study was $28.21 \pm 12$ years with 18 years the least and 42 years the maximum. Among the culture positive cases, $63.16 \%$ were in the third trimester followed by $31.58 \%$ 9n 2nd trimester. The mean age of gestation was 33.62 weeks with standard deviation of 8.2. Minimum period of gestation was 33 weeks and maximum were 42 weeks. Out of 38 ASB cases, $73.68 \%$ were multiparous, $21.05 \%$ were primigravidas and $5.26 \%$ were grand multiparous in present study (Table 1).

Table 1: Demographic details of cases in the study with relation to ASB.

\begin{tabular}{|c|c|c|c|c|}
\hline Characteristics & Frequency & $\begin{array}{l}\text { ASB } \\
\text { positive } \\
\text { (No) }\end{array}$ & $\%$ & $\begin{array}{l}p \\
\text { value }\end{array}$ \\
\hline \multicolumn{5}{|l|}{ Age (years) } \\
\hline$<20$ years & 38 & 4 & 10.53 & \multirow{4}{*}{0.24} \\
\hline $21-25$ years & 248 & 18 & 7.26 & \\
\hline 26-30years & 168 & 10 & 5.95 & \\
\hline$>30$ years & 46 & 6 & 13.04 & \\
\hline \multicolumn{5}{|c|}{ Gestational age } \\
\hline Ist trimester & 146 & 2 & 1.37 & \multirow{3}{*}{0.12} \\
\hline 2nd Trimester & 106 & 12 & 11.32 & \\
\hline 3rd Trimester & 248 & 24 & 9.68 & \\
\hline \multicolumn{5}{|l|}{ Parity } \\
\hline Grand multipara & 11 & 2 & 18.18 & \multirow{3}{*}{0.18} \\
\hline Multipara & 261 & 28 & 10.73 & \\
\hline Primigravida & 228 & 8 & 3.51 & \\
\hline \multicolumn{5}{|c|}{ Educational level } \\
\hline Illiterate & 356 & 32 & 8.99 & \multirow{2}{*}{0.01} \\
\hline Literate & 144 & 6 & 4.17 & \\
\hline \multicolumn{5}{|c|}{ Socio-economic status } \\
\hline Low & 344 & 30 & 8.72 & \multirow{3}{*}{0.03} \\
\hline Middle & 128 & 7 & 5.47 & \\
\hline High & 28 & 1 & 3.57 & \\
\hline \multicolumn{5}{|c|}{ Personal hygiene } \\
\hline Good & 88 & 4 & 4.55 & \multirow{2}{*}{0.69} \\
\hline Poor & 412 & 34 & 8.25 & \\
\hline \multicolumn{5}{|c|}{ Sexual activity (per week) } \\
\hline 1-2 times & 148 & 8 & 5.41 & \multirow{2}{*}{0.01} \\
\hline$>2$ times & 352 & 30 & 8.52 & \\
\hline
\end{tabular}

In present study significant association of ASB was noticed among cases who were illiterate $(84.21 \%)$, with low socio-economic status $(78.95 \%)$ as compared to cases who were literate $(15.79 \%)$ and belonging to middle economic status (18.42\%) (As per Kuppuswamy's socio economic scale).

In the present study, statistically significant association was found between ASB and personal hygiene. $89.47 \%$ of cases with ASB had poor personal hygiene (Using Clothes during menstruation, improper genital washing after urination etc). In 38 cases of ASB, $78.95 \%$ of cases had sexual activity ( $>4$ times a week during pregnancy) and sexual activity with relation to pregnancy was found to be statistically significant in our study ( $\mathrm{p}$ value $<0.05$ ) (Table 1).

Among the isolates, Escherichia coli was the predominant isolate $(42.11 \%)$ followed by Klebsiella pneumoniae (15.79\%), Staphylococcus aureus (15.79\%), Coagulase negative staphylococcus (10.53\%), Citrobacter sp $(10.53 \%)$ and least was Enterococcus sp (5.26\%) (Figure 2).

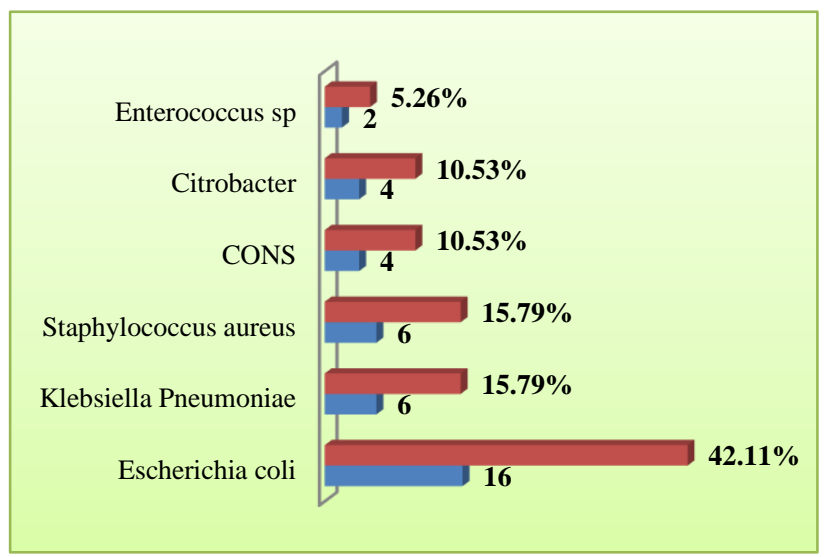

Figure 2: Distribution of urinary isolates from cases of ASB.

Table 2: Percentage of sensitivity of Isolates to antibiotics.

\begin{tabular}{|c|c|c|c|c|c|c|}
\hline Name of the drug & E. coli & K. pneumoniae & S. aureus & CONS & Citrobacter & Enterococcus sp \\
\hline Ampicillin & 66 & ND & 68 & 76 & 76 & 70 \\
\hline Amoxyclav & 86 & 88 & 88 & 90 & 88 & 88 \\
\hline Amikacin & 78 & 82 & 90 & 94 & 92 & ND \\
\hline Cefipime & 78 & 80 & 90 & 94 & 92 & ND \\
\hline Ceftriaxone & 88 & 84 & ND & ND & 90 & ND \\
\hline Ciprofloxacin & 76 & 68 & 74 & 88 & 84 & 88 \\
\hline Clindamycin & ND & ND & 100 & 100 & ND & 100 \\
\hline Cotrimoxazole & 78 & ND & ND & ND & 78 & 78 \\
\hline Cefuroxime & 88 & 88 & ND & ND & 92 & ND \\
\hline Imipenem & 100 & 100 & ND & ND & 100 & ND \\
\hline Meropenem & 100 & 98 & ND & ND & 100 & ND \\
\hline Nitrofurantoin & 94 & ND & ND & ND & ND & ND \\
\hline
\end{tabular}


In present study highest number of bacterial isolates showed sensitivity to Imipenem, Meropenem, Nitrofurantoin, Clindamycin whereas less sensitive to Ampicillin, Cotrimoxazole and Ciprofloxacin (Table 2).

\section{DISCUSSION}

In the present study, the prevalence of ASB among pregnant women attending our hospital was $7.6 \%$ which was similar to findings of Turpin $\mathrm{C}$ et al (7.6\%), Sujatha $\mathrm{R}$ et al $(7.5 \%) .{ }^{7,8}$ However some of the studies reported higher prevalence in the range of $12-20 \%$ in their studies which may be due to differences in the study participants, socioeconomic levels, cultural and religious traditions and personal hygiene and behavior. ${ }^{9}$ Rouse DJ et al in their study stated that screening for pyelonephritis should be done when the prevalence of ASB is more than $2 \% .^{10}$ In our study, there was a higher prevalence of ASB in age group of 20-25 years which is similar to findings of Babu $\mathrm{G}$ et al but contrary to findings of Prasanna et al who reported it among 26-30 years. ${ }^{11,12}$ Advanced maternal age was considered as a risk factor in some of the studies which was contrary to the findings in our study. In our study, prevalence of ASB was higher during $3^{\text {rd }}$ trimester which similar to findings of was Biradhar $\mathrm{S}$ et al, Gayathree L et al while contrary to the findings of Neupane MS et al who reported higher prevalence in $2^{\text {nd }}$ trimester. ${ }^{13-15}$ ASB is more common in $3^{\text {rd }}$ trimester because of urinary stasis produced by gravid uterus and interference with anal and genital hygiene, which provides suitable environment for growth of Escherichia coli. Significant association of ASB was observed among antenatal women who were illiterate and belonging to low socioeconomic status in present study which was also observed in many studies. Illiteracy leads to improper personal hygiene, lack of periodical medical checkup and practicing unsafe sexual practices which leads to invasion of urinary tract by pathogens. ${ }^{16}$ ASB has significant association with sexual activity which was statistically significant in our study as seen in other studies. With sexual intercourse there is an increased probability of transfer of uropathogens into the urethra and associated with ASB among antenatal women. In our study, multiparous women had highest frequency of ASB as reported by many studies universally. This is possibly because multiparity causes descent of pelvic organs and widening of urethral orifice which causes easy access of the uropathogens.

Unlike most of the studies, Escherichia coli was the commonest isolate in present study followed by Klebsiella pneumoniae, Staphylococcus aureus, Citrobacter, CONS and Enterococcus sp. As mentioned in previous reports accurate diagnosis is critical in selection and management of ASB.${ }^{17}$ Escherichia coli is a periurethral commensal and is of faecal origin. Antibiotic of choice for treatment of cases of ASB must be chosen with care to avoid foetal complications. Ampicillin, Amoxycillin, Cephalexin, Nitrofurantoin are chosen as first line of drugs in cases of ASB. The antimicrobial sensitivity and resistance pattern vary from region to region and hospital to hospital in the same region. Multiple etiological factors are responsible for the emergence of resistant strains. In present study gram negative isolates showed $100 \%$ sensitivity to Imipenem, Meropenem and gram positive isolates to Clindamycin. Sensitivity to amikacin in our study was around $82 \%$, Cotrimoxazole was $78 \%$. $94 \%$ of $E$. coli isolates were sensitive to nitrofurantoin in our study which is correlating to findings of Senthinath TJ et al in his study. ${ }^{18}$ all the identified cases of ASB in the study were treated based on the antibiotic sensitivity report. Cases were followed up and no further complications were noticed. Some of the studies report higher complications like premature birth, Low birth weight as a complication in untreated cases of ASB.

\section{CONCLUSION}

To conclude regular screening of antenatal mother during every visit is required to diagnose early cases of ASB to prevent maternal and foetal complications. All the cases of ASB diagnosed should be treated based upon the culture and sensitivity report to prevent unnecessary prescription of antibiotics which can economically burden the patient as well pave a way in development of resistant strains. Hence further initiatives should be undertaken to include urine culture sensitivity as a part of national screening programme to prevent maternal and foetal complications.

\section{Funding: No funding sources}

Conflict of interest: None declared

Ethical approval: The study was approved by the Institutional Ethics Committee

\section{REFERENCES}

1. Balamurugan S, Chaitanya Shah, Jayapriya S., Priyadarshini S, Jeya M, Rao RK. Reagent strip testing (RST) for asymptomatic bacteriuria (ASB) in pregnant women: a cost-effective screening tool in under-resourced settings. JCDR. 2012 May; 6:671-3.

2. Cunningham FG, Gant NF, Laveno KJ. Renal and urinary tract disorders. Williams Obstetrics. 21st Ed. New York: McGraw-Hill Medical Publishing Division; 2001:1253- 4.

3. Schnarr J, Smaill F. asymptomatic bacteriuria and symptomatic urinary tract infections in pregnancy. Eur J Clin Invest. 2008 Sep 24;(38):50-7.

4. Celen S, Oruc AS, Karayalcin R, Saygan S, Unlu S, Polat B, et al. Asymptomatic Bacteriuria and Antibacterial Susceptibility Patterns in an Obstetric Population. ISRN Obstet Gynecol. 2011;2011:721872.

5. Schaeffer AJ, Schaeffer EM. Campbell and Walsh. Text book of Urology. 11 ${ }^{\text {th }}$ Ed. Elsevier;2015:291.

6. Performance Standards for Antimicrobial Disc Susceptibility Tests; Approved Standard-Eleventh Edition M02-A11. Vol.32, No-1. National 
Committee for Clinical Laboratory Standards, Wayne, PA.USA; 2012.

7. Turpin C, Minkah B, Danso K, Frimpong E. Asymptomatic bacteriuria in pregnant women attending antenatal clinic at Komfo Anokye Teaching hospital, Kumasi, Ghana. Ghana Med J. 2007 Mar;41(1).

8. Sujatha R, Nawani M. Prevalence of asymptomatic bacteriuria and its antibacterial susceptibility pattern among pregnant women attending the antenatal clinic at Kanpur, India. Journal of clinical and diagnostic research: JCDR. 2014 Apr;8(4):DC01.

9. Bandyopadhyay S, Thakur JS, Ray P, Kumar R. High prevalence of bacteriuria in pregnancy and its screening methods in north India. J Indian Med Assoc. 2005;103:259-262.

10. Rouse DJ, Andrews WW, Goldenberg RL, Owen J. Screening and treatment of asymptomatic bacteriuria of pregnancy to prevent pyelonephritis: a costeffectiveness and cost-beneficial analysis. Obstet Gynecol. 1995;86:119-23.

11. Girishbabu RJ, Srikrishna R, Ramesh ST. Asymptomatic bacteriuria in pregnancy. Int $\mathrm{J}$ Biol Med Res. 2011;2:7402.

12. Prasanna B, Naimisha M, Swathi K, Shaik MV. Prevalence of asymptomatic bacteriuria in pregnant women, isolates and their culture sensitivity pattern. Int J Curr Microbiol App Sci. 2015;4(8):28-35.

13. Kerure SB, Surpur R, Sagarad SS, Hegadi S. Asymptomatic bacteriuria among pregnant women. Int J Reprod Contracept Obstet Gynecol. 2013;2(2):213-6.

14. Gayathree L, Shetty S, Deshpande SR, Venkatesh DT. Screening for asymptomatic bacteriuria in pregnancy: An evaluation of various screening tests in Hassan District Hospital, India. J Clin Diagn Res. 2010;4(4):2702-6.

15. Neupane MS, Dhakal KS, Neupane HC, Adhikari S, Aryal B. Asymptomatic Bacteriuria among Pregnant Women attending the Outpatient Clinics of Chitwan Medical College teaching hospital in Chitwan, Nepal. IRJP. 2012;3(11):78-80.

16. Oli AN, Okafor CI, Ibezim EC, Akujiobi CN, Onwunzo MC. The prevalence and bacteriology of asymptomatic bacteriuria among antenatal patients in Nnamdi Azikiwe University Teaching Hospital Nnewi; South Eastern Nigeria. Nigerian J Clin Pract. 2010;13(4):40912.

17. Chandel LR, Kanga A, Thakur K, Mokta KK, Sood A, Chauhan S. Prevalence of Pregnancy Associated Bacteriuria: A study done in a tertiary care Hospital. J Obstet Gynecol India. 2012; 62(5):511-4.

18. Senthinath TJ, Rajalaksmi PC, Keerthana R, Vigneshwari RS, Revathi RS, Prabhu N, et al. Prevalence of asymptomatic bacteriuria among antenatal women in rural tertiary care hospital, Tamilnadu, India. Int J Curr Microbiol App Sci. 2013;2(1):80-5.

Cite this article as: Cooly V, Bandaru S,

Salicheemala B, Surayapalem S. Prevalence and associated risk factors of asymptomatic bacteriuria among antenatal women attending a health care center: one year study. Int J Reprod Contracept Obstet Gynecol 2017;6:5472-6. 